\title{
An intraoperative device to restore femoral offset in total hip arthroplasty
}

\author{
Enxing Xue ${ }^{1 \dagger}$, Zhen $\mathrm{Su}^{2 \dagger}$, Chengwang Chen ${ }^{1}$, Paul Kim Chiu Wong ${ }^{3}$, Hong Wen ${ }^{1}$ and Yu Zhang ${ }^{1 *}$
}

\begin{abstract}
Background: Leg length discrepancy (LLD) after total hip arthroplasty (THA) can lead to unsatisfactory outcome. Our objective was to design and evaluate a simple and reliable intraoperative device (Length-offset Lever) to minimize leg length discrepancy.

Methods: This device was used in 51 patients undergoing primary total hip replacements. The leg length discrepancy was measured pre- and postoperatively based on plain radiographs.

Results: Preoperative radiographic leg length discrepancy averaged $13.5 \pm 6.2 \mathrm{~mm}$. Leg length discrepancy showed significant improvement, with a postoperative average of $4.1 \pm 2.3 \mathrm{~mm}(p<0.0001)$. There were no complications associated with this device.

Conclusions: The 'Length-offset Lever' is a useful intraoperative tool to restore anatomic femoral offset and height of femoral head.
\end{abstract}

Keywords: Leg length discrepancy, Total hip arthroplasty, Femoral offset, Device

\section{Introduction}

One of the main goals of total hip arthroplasty is to restore and optimize normal hip biomechanics. Femoral offset is defined as the perpendicular distance between the centre of femoral head and the long axis of the femoral component. Charnley [1] has highlighted the importance of femoral offset on the hip joint forces.

Leg length discrepancy (LLD) after total hip arthroplasty (THA) is one of the leading causes for unsatisfactory outcomes [2-7]. Various methods have been described to measure LLD directly or indirectly, during THA [8-11].

This paper describes a simple, reliable and safe intraoperative device, Length-offset Lever. It can be used to perform THA, done through a direct lateral approach, without requiring additional equipment, incisions, or radiographs (Figure 1). It is a 'two-in-one' device used to measure femoral offset, intraoperatively.

\footnotetext{
* Correspondence: drzhangyu@hotmail.com

${ }^{\dagger}$ Equal contributors

'Department of Orthopaedic Surgery, The Second Affiliated Hospital and Yuying Children's Hospital of Wenzhou Medical University, 109 Xueyuan West Road, Wenzhou, Zhejiang 325000, China

Full list of author information is available at the end of the article
}

\section{Methods}

\section{Patients}

In our study, preoperative diagnoses were Crowe I or II developmental dysplasia of the hip in 23 patients, osteonecrosis in 12, osteoarthritis in 10, and rheumatoid arthritis in 6 . Of all the patients, 22 were male and 29 were female. This study was approved by the ethics committee of The Second Affiliated Hospital of Wenzhou Medical University, and informed consents were obtained from participants or their authorized persons.

We studied a total of 51 patients undergoing primary THA between March 2008 and December 2011, using the Length-offset Lever. Revisions, THAs requiring osteotomies, and first operations of staged bilateral THAs were excluded. All THAs in this study were performed with cementless fixation utilizing direct lateral approach. Synergy stems (Smith \& Nephew, Andover, MA, USA) were used in 28 cases, Tri-lock and Corail stems (Depuy, Warsaw, IN, USA) in 19 cases, and M/L stems (Zimmer, Warsaw, IN, USA) in 4 cases.

\section{Surgical technique}

Fifty-one patients were placed in the lateral position and direct lateral approach to the hip was used. Length- 


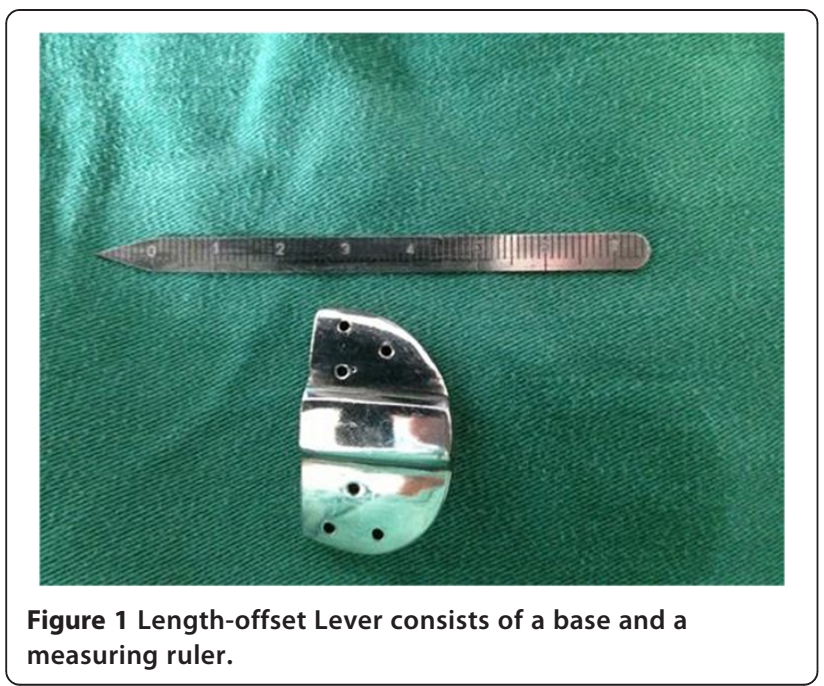

offset Lever consisted of a 'base' and 'measuring ruler'. After dislocation of the hip and prior to the femoral neck cut, we determined the center of the femoral head with the following procedures: first, we let compasses be perpendicular to the plane of the femoral head; then we find three points on the boundary of the femoral head and the center is equidistant to three points by compasses (Figure 2), the 'base' unit was fixed to the anterior aspect of the greater trochanter using K-wires. The anatomic femoral offset was measured after sliding the ruler's tip to the centre of the femoral head (Figure 3A). The 'ruler' was then removed, leaving the 'base' alone. After inserting the trial components, the 'ruler' was reinserted into the 'base', and the new offset of the femoral head was then measured (Figure 3B). If we planned to lengthen the leg by $10 \mathrm{~mm}$, we can have the femoral

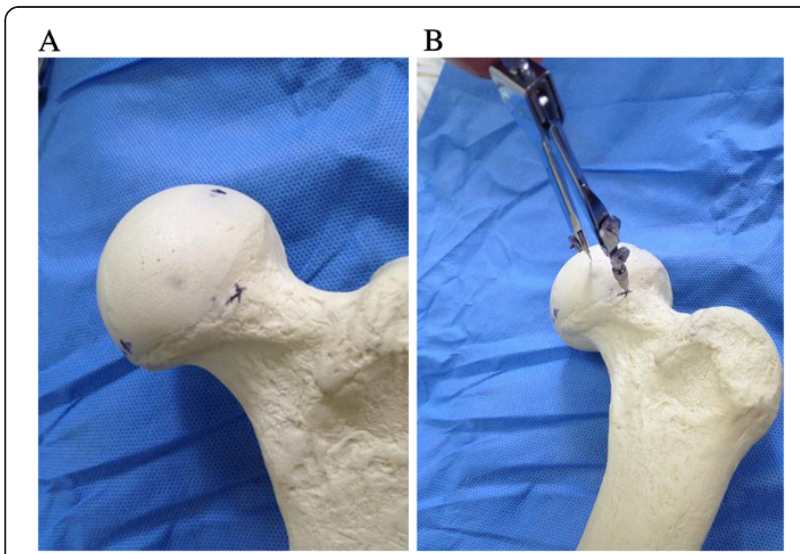

Figure $\mathbf{2}$ The method to determine the center of the femoral head. (A) Three points on the boundary of femoral head. (B) The center is equidistant to three points by compasses.

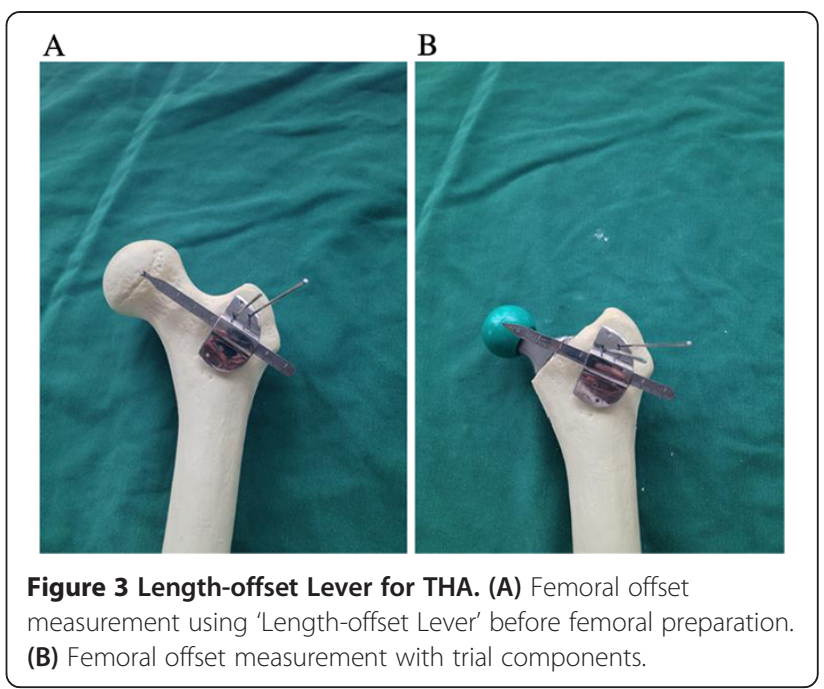

head trial $10 \mathrm{~mm}$ above the tip of the ruler. The fovea should be cleared of soft tissue to evaluate acetabular depth, and transverse acetabular ligament can be used to confirm orientation and height of the acetabular component.

\section{Postoperative management}

Leg length discrepancy was evaluated from an anteroposterior radiograph of the pelvis with both hips in neutral position (Figure 4). Radiographs were recorded on PACS (Picture Archiving \& Communication System, INFINITT Co., Ltd, Guro-gu, Seoul, Korea) with a resolution of $1,536 \times 2,048$ pixels. A horizontal line was drawn through the bottom of the ischial tuberosities. Discrepancy in leg length was measured using the relationship between this line and the most prominent point of the lesser trochanter.

Clinical evaluations were based on the Harris hip scores [12]. Student's $t$ tests were performed to determine statistical significance.

The postoperative average of femoral offset compared to the contralateral normal one on radiographs was recorded on PACS. Statistical analysis of the measurements was conducted using paired $t$ tests, setting the level of significance at 0.05 .

\section{Results}

Mean age of patients was 65.59 years (range 18 to 84 ). The average follow-up period was 18 months (range 12 to 30). Preoperative radiographic leg length inequality averaged $13.5 \pm 6.2 \mathrm{~mm}$ (range +33 to $-12 \mathrm{~mm}$ ). Leg length discrepancy showed significant improvement, with a postoperative average of $4.1 \pm 2.3 \mathrm{~mm}$ (range 0 to 5) $(p<0.0001)$. None of the patients required shoe lifts for equalization of leg lengths nor complained of 

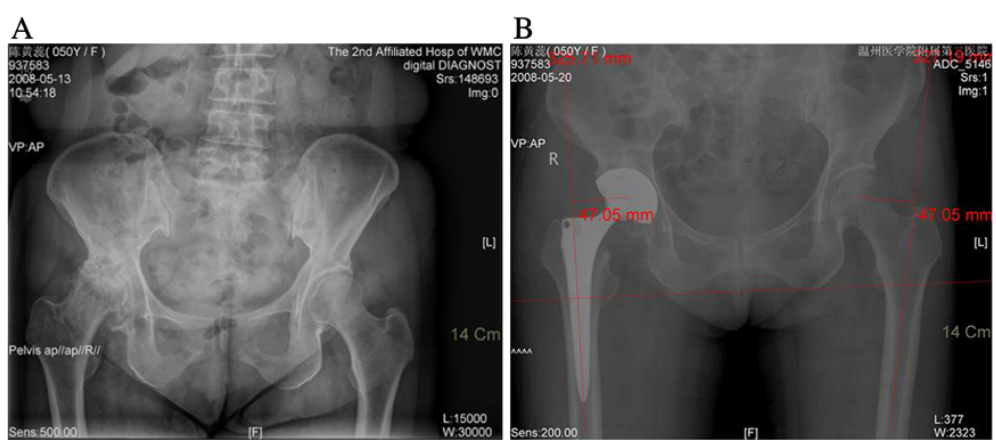

Figure 4 Radiographs of pelvis of a 50-year-old female. Presented with severe pain and limited range of motion in her right hip, secondary to osteoarthritis. (A) Preoperative limb-length inequality was $14.6 \mathrm{~mm}$. (B) THA was performed using the Length-offset Lever (Figure 1). Postoperative limb-length inequality was $0 \mathrm{~mm}$. The patient had excellent pain relief and functional results following the THA and no complications.

leg length discrepancy, postoperatively. No complications associated with Length-offset Lever were observed in these patients. There were no complications of dislocation, infection, fracture, or sciatic nerve palsy.

Harris hip scores significantly improved postoperatively. They increased from $45.9 \pm 14.2$ points preoperatively to $83.3 \pm 12.6$ points at the latest follow-up $(p<0.0001)$.

The paired $t$ test comparisons showed statistically no significance difference between postoperative average of femoral offset and the contralateral normal one $(p>0.50)$.

\section{Discussion}

It can be a difficult task to maintain hip stability while trying to achieve equal leg length during THA [13-17]. A longer neck length is often used to improve the stability of THA. With modern femoral component designs, surgeons have more options to balance the leg length while maintaining hip stability. One example is the modular femoral neck component, which allows for flexible adjustment of femoral offset and version.

Konyves and Bannister [2] found that patients with lengthened operative legs had poorer Oxford hip scores than those that were shorter or had equal leg lengths. They believed that LLD was most commonly caused by over-lengthening of the prosthetic head-neck distance. The accuracy of femoral offset measurement using preoperative plain radiographs is affected by the rotation of the femur and pelvic tilt $[18,19]$. Surgeons, in the past, have used methods or devices like pins, rulers, and calipers for intraoperative measurement of leg length discrepancy $[8,10,20,21]$. It can be employed easily for intraoperative limb length measurement during THA, without creating a separate incision. The average leg length discrepancy postoperative was $4.2 \mathrm{~mm}$ in our study. No complications associated with the use of this device were observed. None of the patients expressed dissatisfaction about limb-length inequality after surgery. Safety and effectiveness of the Length-offset Lever was demonstrated in our study.

The device is effective when the leg length discrepancy is secondary to femoral deformity with minimal acetabular bone loss. Its use may not be appropriate for cases with significant acetabular dysplasia and this device does not measure the overall leg length or global offset.

There are many methods to restore femoral offset to eliminate the leg length discrepancy. For example, preoperative templating is mentioned as a common method for many surgeons which is an indirect method, its result is affected by radiographic magnification and position of patients when they had X-ray, templating overlays enlarged by a uniform factor may not be perfectly accurate. The shuck test and the dropkick test both rely on soft tissue tension as a surrogate indicator of limb length, motor blockade from spinal or epidural anesthesia may cause them to be less reliable than standard general anesthesia [22]. Surgeons also should not rely solely on the intraoperative leg-to-leg comparison because it is limited by greater adduction on the operative side and inaccuracy of palpation of landmarks through surgical drapes. Another method [23] was performed with procedures of stitching a suture into the skin superior to the surgical field and drilling a pin into the ilium bicortically, superior to the acetabulum and perpendicular to the table. It had the drawbacks of the potential loosening of the pin and positional variation of the hip during measurement. Our tool has many advantages, such as ease of use, low cost, unaffected by soft tissue tension, and measurement of the femoral offset directly and intraoperatively.

In conclusion, the Length-offset Lever is a useful intraoperative tool to restore anatomic femoral offset and height of femoral head. 


\section{Abbreviations}

LLD: leg length discrepancy; THA: total hip arthroplasty.

\section{Competing interests}

The authors declare that they have no competing interests.

\section{Authors' contributions}

EX and ZS contributed equally to this paper. Both wrote the manuscript, participated in the design of the study and performed the statistical analysis. YZ was involved in the statistical analysis, preparation of the figures, data interpretation, study design, and writing of the manuscript. PKCW was involved in the data interpretation and writing of the manuscript. CC and HW were involved in the review of published work and data interpretation. All authors read and approved the final manuscript.

\section{Author details}

${ }^{1}$ Department of Orthopaedic Surgery, The Second Affiliated Hospital and Yuying Children's Hospital of Wenzhou Medical University, 109 Xueyuan West Road, Wenzhou, Zhejiang 325000, China. ${ }^{2}$ Department of Nephrology, The First Affiliated Hospital of Wenzhou Medical University, Wenzhou, Zhejiang 325000, China. ${ }^{3}$ Department of Surgery, University of Toronto, 650 Sammon Ave. Suite 301, Toronto, ON M4C 5M5, Canada.

Received: 25 November 2013 Accepted: 27 June 2014

Published: 19 July 2014

\section{References}

1. Charnley J: Low Friction Arthroplasty of the Hip: Theory and Practice, Volume 3. New York: Springer-Verlag; 1979.

2. Konyves A, Bannister GC: The importance of leg length discrepancy after total hip arthroplasty. J Bone Joint Surg (Br) 2005, 87:155

3. Yamaguchi T, Naito M, Aasayama I, Ishiko T: Total hip arthroplasty: the relationship between posterolateral reconstruction, abductor muscle strength, and femoral offset. J Orthop Surg (Hong Kong) 2004, 12:164.

4. McGrory BJ, Morrey BF, Cahalan TD, An KN, Cabanela ME: Effect of femoral offset on range of motion and abductor muscle strength after total hip arthroplasty. J Bone Joint Surg (Br) 1995, 77-B:865.

5. Asayama I, Naito M, Fujisawa M, Kambe T: Relationship between radiographic measurements of reconstructed hip joint position and the Trendelenburg sign. J Arthroplasty 2002, 17:747.

6. Asayama I, Chammongkich S, Simpson KJ, Kinsey TL, Mahoney OM: Reconstructed hip joint position and abductor muscle strength after total hip arthroplasty. J Arthroplasty 2005, 20:414.

7. Sakalkale DP, Sharkey PF, Eng K, Hozack WJ, Rothman RH: Effect of femoral component offset on polyethylene wear in total hip arthroplasty. Clin Orthop 2001, 388:125.

8. Naito M, Ogata K, Asayama I: Intraoperative limb length measurement in total hip arthroplasty. Int Orthop 1999, 23:31.

9. Ranawat CS, Rajesh R, Rodriquez JA, Bhende HS: Correction of limb length inequality during total hip arthroplasty. J Arthroplasty 2001, 16:715.

10. Shiramizu K, Naito M, Shitama T, Nakamura Y, Shitama H: L-shaped caliper for limb length measurement during total hip arthroplasty. $J$ Bone Joint Surg (Br) 2004, 86:966.

11. Takigami I, Itokazu M, Itoh Y, Matsumoto K, Yamamoto T, Shimizu K: Limb-length measurement in total hip arthroplasty using a calipers dual pin retractor. Bull NYU Hosp Jt Dis 2008, 66(2):107.

12. Harris VM: Traumatic arthritis of the hip after dislocation and acetabular fractures: treatment by mold arthroplasty. An end-result study using a new method of result evaluation. J Bone Joint Surg Am 1969, 51:737.

13. Kelley SS: High hip center in revision arthroplasty. J Arthroplasty 1994, 9:503.

14. Charles MN, Bourne RB, Davey JR, Greenwald AS, Morrey BF, Rorabeck CH: Soft-tissue balancing of the hip: the role of femoral offset restoration. Instr Course Lect 2005, 54:131.

15. Bourne RB, Rorabeck CH, Patterson JJ, Guerin J: Tapered titanium cementless total hip replacements: a 10- to 13-year follow-up study. Clin Orthop 2001, 393:112.

16. Konyves $A$, Bannister GC: The importance of leg length discrepancy after total hiparthroplasty. J Bone Joint Surg (Br) 2005, 87-B:155.

17. Steinberg B, Harris WH: The offset problem in total hip arthroplasty. Contemp Orthop 1992, 24:556.
18. Plaass $C$, Clauss $M$, Ochsner PE, Ilchmann T: Influence of leg length discrepancy on clinical results after total hip arthroplasty: a prospective clinical trial. Hip Int 2011, 21:441

19. Tannast M, Zheng G, Anderegg C, Burckhardt K, Langlotz F, Ganz R, Siebenrock KA: Tilt and rotation correction of acetabular version on pelvic radiographs. Clin Orthop Relat Res 2005, 438:182.

20. McGee HMJ, Scott JHS: A simple method of obtaining equal leg length in total hip arthroplasty. Clin Orthop Relat Res 1985, 194:207.

21. Itokazu M, Masuda K, Ohno T, Itoh Y, Takatsu T, Wenyi Y: A simple method of intraoperative limb length measurement in total hip arthroplasty. Bull Hosp Jt Dis 1997, 56:204.

22. Sathappan SS, Ginat D, Patel V, Walsh M, Jaffe WL, Di Cesare PE: Effect of anesthesia type on limb length discrepancy after total hip arthroplasty. J Arthroplasty 2008, 23(2):203-209.

23. Ng VY, Kean JR, Glassman AH: Limb-length discrepancy after hip arthroplasty. J Bone Joint Surg Am 2013, 95(15):1426-1436.

doi:10.1186/s13018-014-0058-7

Cite this article as: Xue et al:: An intraoperative device to restore femoral offset in total hip arthroplasty. Journal of Orthopaedic Surgery and Research 2014 9:58.

\section{Submit your next manuscript to BioMed Central and take full advantage of:}

- Convenient online submission

- Thorough peer review

- No space constraints or color figure charges

- Immediate publication on acceptance

- Inclusion in PubMed, CAS, Scopus and Google Scholar

- Research which is freely available for redistribution 